\title{
Active Rectifier for Uninterruptable Power Supply
}

\author{
Andrew Stepanov, Riga Technical University, Valdis Bogdans, Riga Technical University, \\ Pavel Suskis, Riga Technical University, Ilya Galkin, Riga Technical University
}

\begin{abstract}
The paper contains analysis of power factor correction circuits that is made in the context of elaboration of uninterruptable power supply system. Various correctors have been estimated analytically, by means of simulation and experimentally. The most significant attention has been paid to the efficiency of the analyzed converters and their compatibility with modular approach to development of power converters.
\end{abstract}

Keywords: uninterruptible power supply systems, power factor, circuit simulation

\section{INTRODUCTION}

The proposed uninterruptable power supply system (UPSS) provides a stable electrical supply for its load not only from the mains or traditional energy storage - battery, but also from alternative/extra energy resources like solar panels, fuel cells or diesel-generator. In case of higher power demand (that is usually temporary) UPSS may supply the load also from a supercapacitor.

In order to get the maximum power from diesel-generator it is very important to load it with sinusoidal current with no phase shift. The same can be applied to the mains - its current must be sinusoidal and purely active. To resolve the problem of non-sinusoidal current an active rectifier with power factor correction (PFC) must be used. This paper contains the analysis of efficiency of various PFC circuits.

There are several commonly used topologies of PFC circuits. Although they are quite different they contain similar blocks of the transistors and/or diodes connected in series. This makes a modular approach described, for example, in [1] possible. The described modules include transistors (connected as a half-bridge), their transistor drivers, circuits for voltage/current measurements and interface for control equipment. The utilized system developed in Riga Technical University is similar, but has some significant differences [2]:

- modules include 2 DC-link capacitors connected in series (Fig. 1-a) that allow testing half-bridge PFC circuits with DC-link voltage up to $800 \mathrm{~V}$; One of capacitors can be shunted if not necessary in the particular configuration;

- they provide voltage measurements on both DC-link capacitors, helping to avoid voltage unbalance;

- they have optical control interface, to maximize control device safety and control signal noise immunity;

- they have liquid cooling system that allow to minimize volume of primary heat sinks.

For the given research the modules have been reconfigured so that (Fig. 1-b) the third voltage is measured between the midpoint of capacitors and the input connector. Thus measurement of the input voltage of PFC becomes possible.

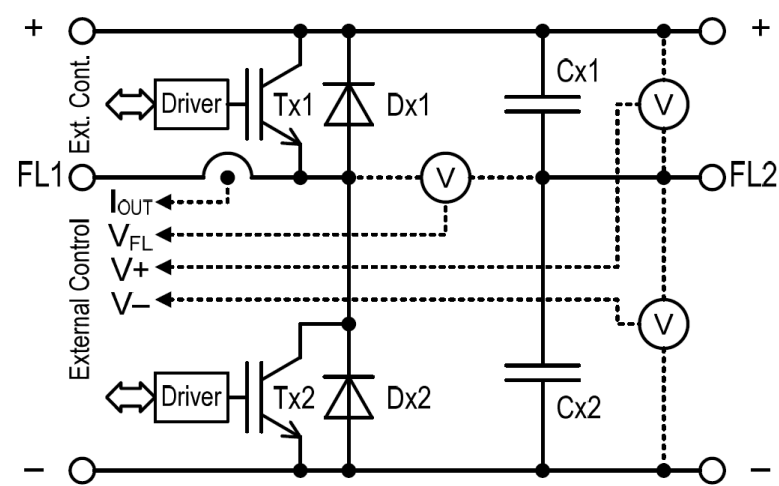

a) generalized configuration of the module;

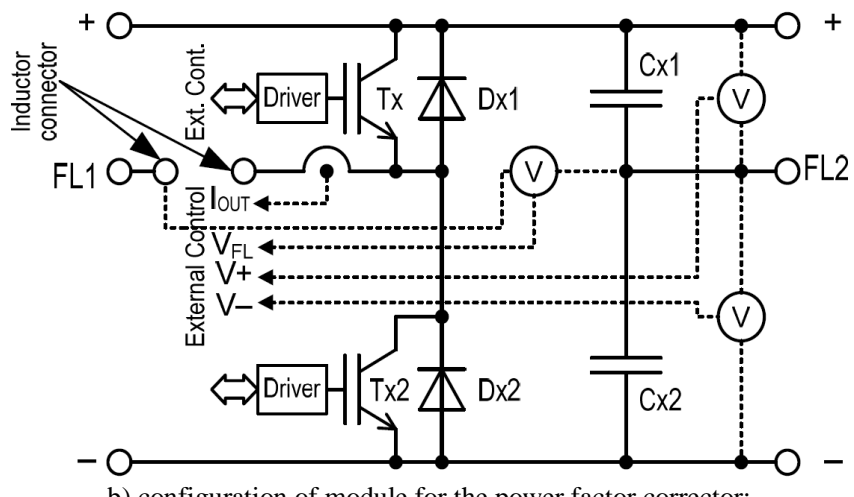

b) configuration of module for the power factor corrector;

Fig. 1. Power board of versatile modular converter.

The modules can be controlled from ezDSP kit (with TI's TMS320 DSP) or dSpace DS1103 debugging hardware or from any other control equipment via the corresponding adaptor. However, the microprocessor training kit available in the lab (with MCU MSP430) that has been utilized for the purpose of initial debugging is directly compatible with the modules. The dSpace control solution is preferable because it offers excellent compatibility with Matlab-Simulink models that fasten the debugging process.

\section{SIMULATION OF PFC CONVERTERS}

The initial estimation of PFC converters was made by means of the simulation in Matlab-Simulink. For the faster transfer from a model to control solution the models have topology of the power modules. For this reason the MatlabSimulink models consist of the same 3 subsystems: power converter, measurement board and control system. Driver board is omitted in the model because power switches in Matlab-Simulink model can be driven directly by logical elements. 


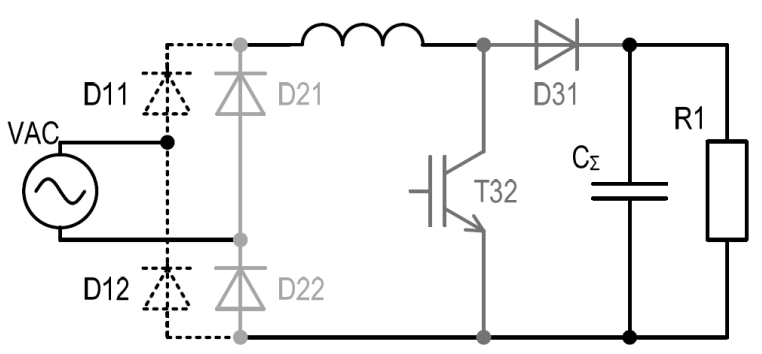

Fig. 2. Boost PFC converter.

Depending on the modeled PFC circuit the model of its power board consists of one or more half-bridges, 1 or $2 \mathrm{DC}$ link capacitors, input inductor, AC voltage source and resistive load. Besides that voltage dividers for voltage measurement are also installed in the power board.

The model of the measurement boards consist of the transfer function of isolation amplifier HCPL-7400 and Hall sensor LEM LTS-15. These elements ensure the same voltage levels as the real feedbacks in the experimental PFC converters. The transfer functions are composed as proportional elements.

The control board represents the control core composed of Matlab-Simulink blocks. During the experiments it is converted into the executable program for dSpace DS1103 module.

\section{A. Single-phase boost PFC converter}

The power board subsystem of Matlab-simulink model for this converter is shown in Fig. 3. Internal Matlab models of elements are used. However, their parameters (inductance/internal resistance of the coil, capacitance/ESR of capacitor, voltage drop/dynamic resistance and the other parameters of power semiconductors, the resistors of the dividers etc.) are chosen in correspondence with the real elements of the modular converter.

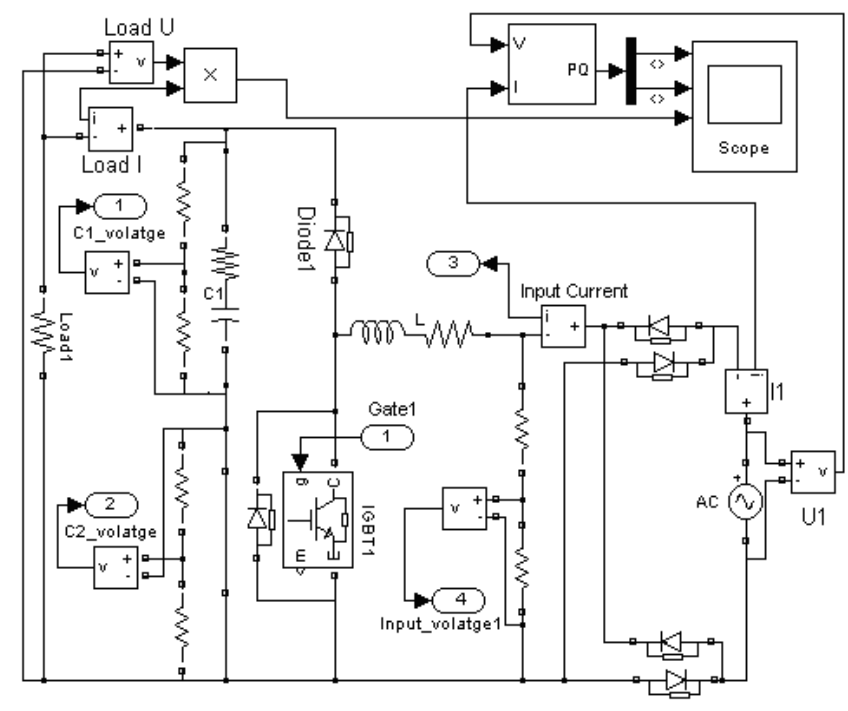

Fig. 3. Matlab model of power subsystem of boost PFC converter.

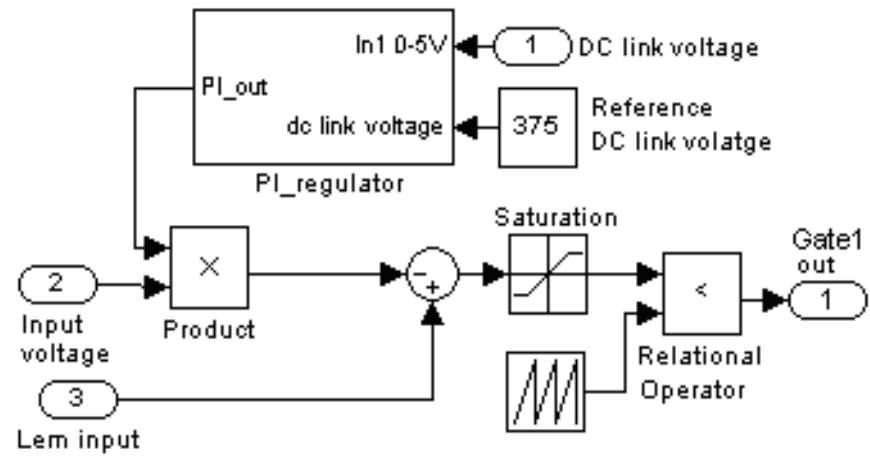

Fig. 4. Control circuit of boost rectifier.

This is the most popular topology (Fig. 2 - here and below elements of the 1st module are dashed, 2nd - light grey, 3rd dark grey while 4 th - black) utilized as a part of high power factor rectifiers in power supplies and electric drives.

The line current simultaneously flows through three semiconductors that is the most significant disadvantage of this PFC. For this reason the overall efficiency of such converters is smaller than with the other topologies. Line diodes (D1x and D2x) can be of low recovery capabilities while boost diode $\mathrm{D} 31$ must be fast.

The utilized power modules are of half-bridge topology that includes 2 diode/transistor modules connected in series and 2 capacitors also in series connection with the total maximal voltage of $1000 \mathrm{~V}$. In the case of boost PFC rectifier only one transistor is required, but the maximal voltage of DC-link capacitor is $450 \mathrm{~V}$. That is why the module has been reconfigured: its upper transistor is switched off all the time, while the lower capacitor $(\mathrm{C} 2)$ is replaced with $0 \mathrm{Ohm}$ shunt resistance (in reality it is a $4 \mathrm{~cm}$ long piece of wire). Therefore there is no capacitor's midpoint that gives few advantages: the equivalent capacitance is two times higher and the voltage meter V3 can be used more easily for input voltage measurement.

In the model (Fig. 3) voltage meter U1 and current meter I1 are used only for calculation of input active and reactive power. In a similar way voltage meters "Load I" and "Load U" are utilized to find the output power. These parameters ("Input active power" and "Load power") together allow evaluation of the efficiency of the converter. The control circuit of boost PFC is given in Fig. 4. It is based on a typical reference follower included in a closed loop (for DC voltage).

\section{B. Single-phase boost interleaved PFC converter}

This topology is similar to previous, but it has 2 boost stages (Fig. 5) that are controlled by shifted signals with equal duty cycle (Fig. 6). This control algorithm gives current ripple in inductors also with shift. Due to that total input current has smaller ripple than in each individual inductor. At the moment when duty cycle is $50 \%$, the ripple of currents are shifted exactly by the half of modulation period. In the resulting current this ripple is, therefore, compensated and the total input current is without any ripple. 


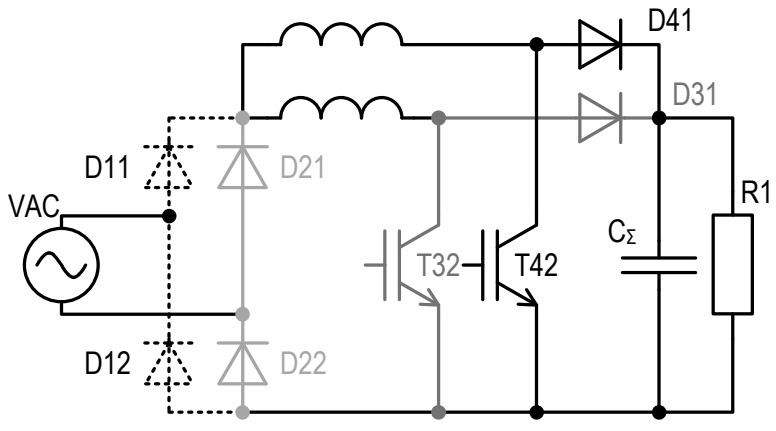

Fig. 5. Interleaved boost PFC converter.

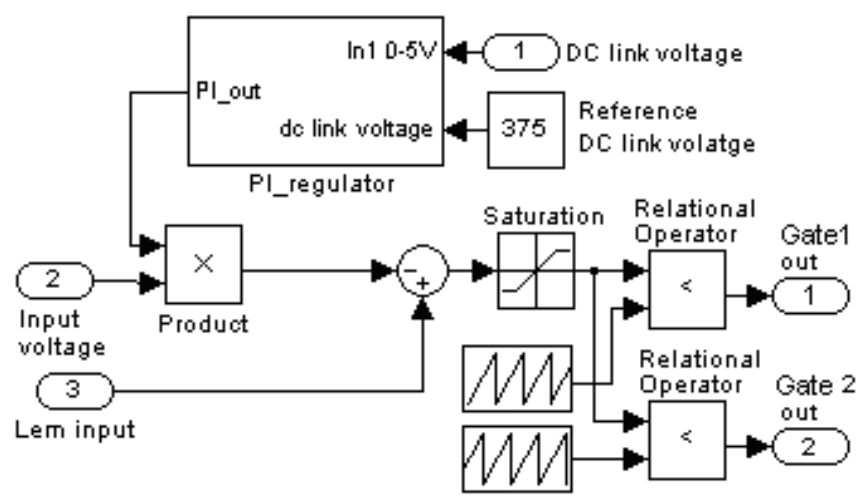

Fig. 6. Control circuit of the boost interleaved rectifier.

\section{Bridgeless single-phase PFC converters}

The main advantage of the described circuits is absence of the diode bridge (Fig. 7 to Fig. 9). That is why the line current simultaneously flows through 2 semiconductor switches that ensure higher efficiency of the converter. All these topologies are mostly similar and have equal parameters of their elements at the same power. PFC converters in Fig. 7 and Fig. 8 are just simplified versions of single-phase full bridge converter. However both these topologies are unidirectional while the full bridge converter can operate also as an inverter.

The basic bridgeless PFC converter (Fig. 7) can be controlled in similar way as boost PFC converter (Fig. 4). Both switches can be controlled by the same signal and in real converter they can be driven even by the same driver.

The bridgeless totem-pole PFC converter (Fig. 8) includes transistors forming a complete transistor leg that have to be controlled by different drivers and different signals (Fig. 10). Each of these transistors operates only within one half-wave.

The full transistor bridge PFC converter (Fig. 9) is the most versatile circuit. For unidirectional power flow it can be controlled like two previous circuits (Fig. 4 and Fig. 10). However, if the power flow is bidirectional it is necessary to control all 4 switches (Fig. 11).

Modular test bench for the testing of the described converters is the same and consist of 2 modules. Due to that the power subsystem of Matlab-Simulink model also consists of 2 transistor legs (Fig. 12).

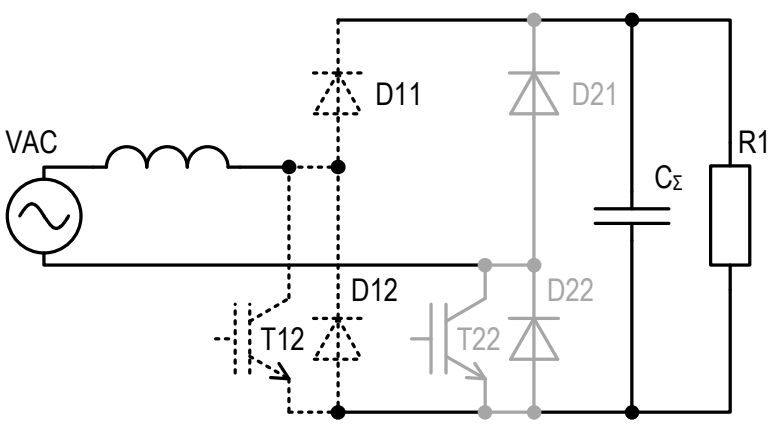

Fig. 7. Basic bridgeless PFC converter.

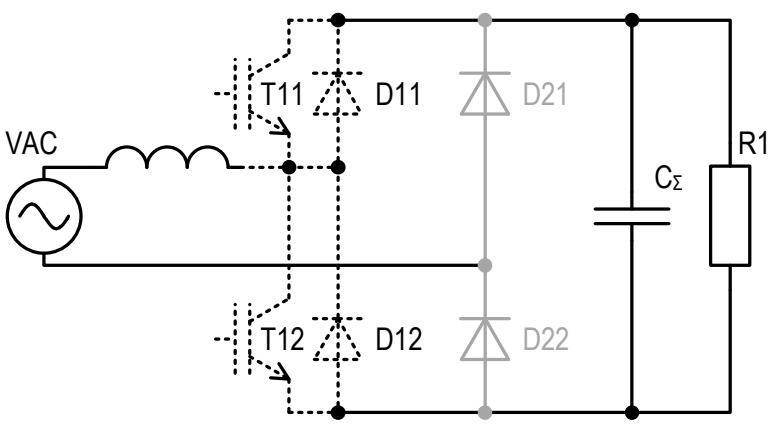

Fig. 8. Bridgeless totem-pole PFC converter.

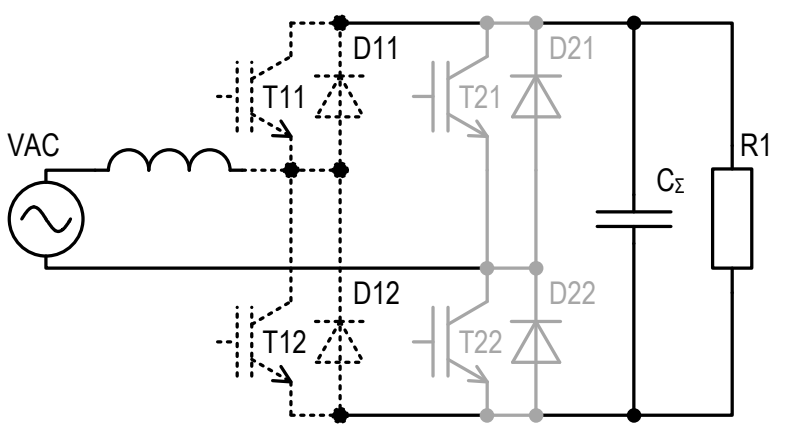

Fig. 9. Full-bridge PFC converter/inverter.

In the bridgeless PFC converter (Fig. 7) only transistors of IGBT1 and IGBT2 packages are driven while the reverse diodes of IGBT3 and IGBT4 operate as boost diodes.

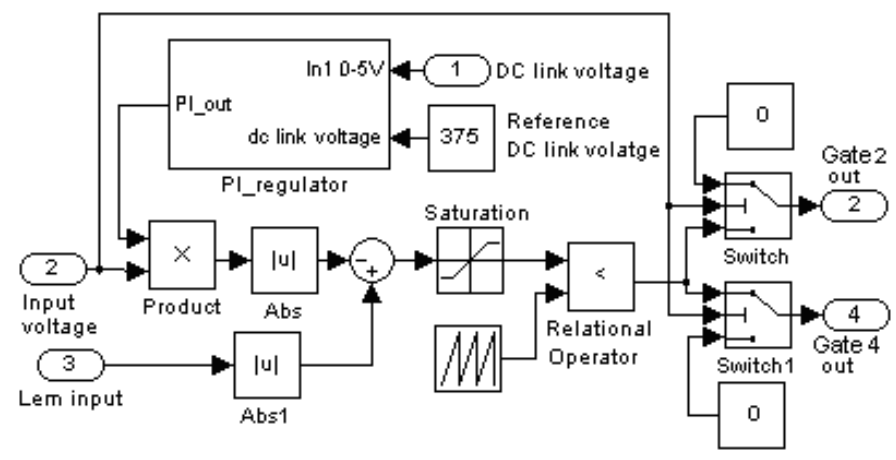

Fig. 10. Control circuit for bridgeless totem converter. 


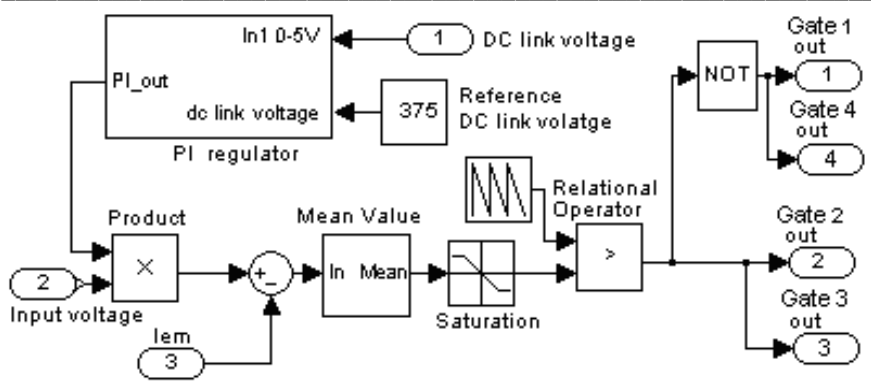

Fig. 11. Control circuit for full-bridge converter.

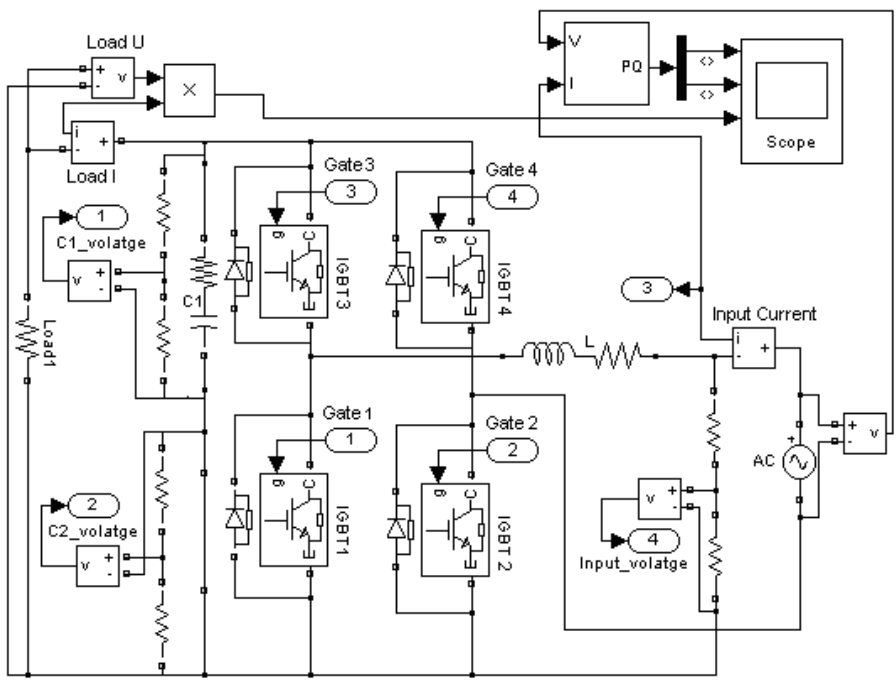

Fig. 12. Matlab model of "power board" subsystem for bridgeless converters.

\section{Single-phase half-bridge converter}

The main advantage of the half-bridge converter (Fig. 13) is an extremely small number of semiconductor switches (only 1) in the line current path that leads to higher efficiency. The half-bridge also allows compensation of reactive power and ensures bi-directional power flow. The main drawback of this converter is 2 times higher voltage across its DC-link.

The power circuit subsystem of the Simulink model of the half-bridge PFC is shown in Fig. 14. Unlike the most of previously mentioned PFC converters this circuit utilizes both DC-link capacitors.

Control algorithm is similar to that of bridgeless totem rectifier topology (Fig. 10). However, for bidirectional power flow it has to be controlled like full-bridge converter.

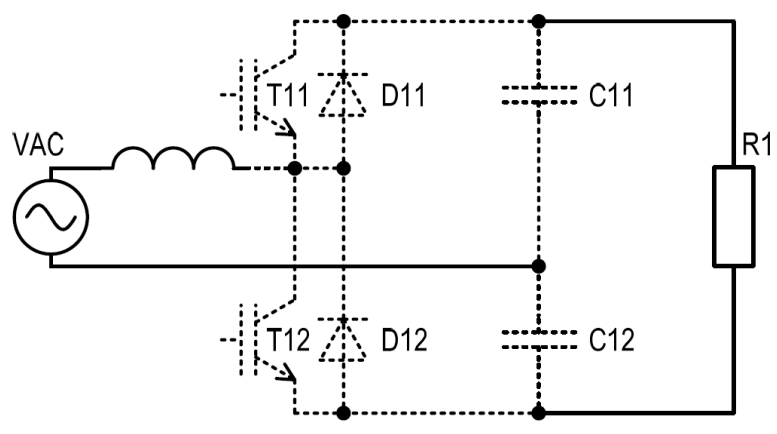

Fig. 13. Half-bridge PFC converter.

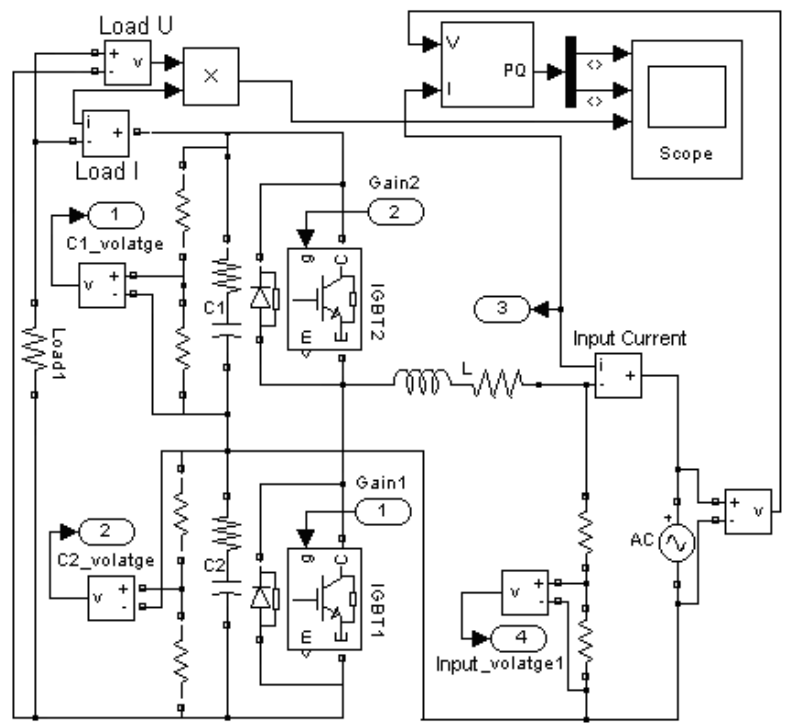

Fig. 14. Half-bridge PFC converter.

\section{SiMULATION RESUlTS}

All the above described converters were simulated at $25 \%$ and $75 \%$ of the rated power of $4400 \mathrm{~W}$ (that gives values of $1100 \mathrm{~W}$ and $3300 \mathrm{~W}$ ). The obtained simulation results (Table I) show that at all loads all converters ensures the efficiency higher than $96 \%$. The corresponding THD depends on the output power and, most likely, is defined by the distortions at switching frequency. The topology of PFC has very little effect on THD (except, of course, interleaved circuit). Table II reveals also the operation of the half-bridge and full-bridge PFC as reactive power compensators. Other advantages and disadvantages of the described circuits are compared in Table III. The obtained information proves the functionality of all discussed circuits and lead to the conclusion that no preferences can be made after the simulation.

\section{TABLE I}

RESUlts OF SimUlation OF ACTIVE PFC AT 75\% AND 25\% OF POWER

\begin{tabular}{|l|c|c|c|c|}
\hline \multirow{2}{*}{$\begin{array}{l}\text { Converter } \\
\text { topology }\end{array}$} & \multicolumn{2}{|c|}{ Efficiency (\%) } & \multicolumn{2}{c|}{ THD (\%) } \\
\cline { 2 - 5 }$@ \mathbf{9 5 \%}$ & @25\% & $@ \mathbf{7 5 \%}$ & $@ \mathbf{2 5 \%}$ \\
\hline Boost & 96 & 97 & 5 & 14 \\
\hline Half-bridge & 97 & 96 & 6 & 18 \\
\hline Bridgeless & 97 & 96 & 5 & 13 \\
\hline Bridgeless totem & 97 & 96 & 5 & 14 \\
\hline Full-bridge & 96 & 97 & 6 & 19 \\
\hline Interleaved & 97 & 96 & 4 & 8 \\
\hline
\end{tabular}

TABLE II

COMPENSATION OF REACTIVE POWER OF ACTIVE PFC AT 10\% OF POWER

\begin{tabular}{|l|c|c|c|c|}
\hline $\begin{array}{l}\text { Converter } \\
\text { topology }\end{array}$ & $\begin{array}{c}\text { Efficiency } \\
(\boldsymbol{\%})\end{array}$ & $\begin{array}{c}\text { THD } \\
(\boldsymbol{\%})\end{array}$ & cos (f) & $\begin{array}{c}\text { Reactive } \\
\text { power } \\
\text { (VAR) }\end{array}$ \\
\hline Half-bridge & 93.9 & 3.5 & 0.77 & -4112 \\
\hline Half-bridge & 94.9 & 4.3 & 0.85 & 3051.3 \\
\hline Full-bridge & 94.5 & 3.9 & 0.8 & -3780 \\
\hline Full-bridge & 91.7 & 3 & 0.7 & 5060 \\
\hline
\end{tabular}


TABLE III

COMPARISON OF ACTIVE PFC

\begin{tabular}{|c|c|c|c|c|c|c|c|c|}
\hline $\begin{array}{l}\text { Converter } \\
\text { topology }\end{array}$ & 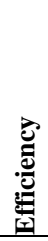 & 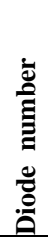 & 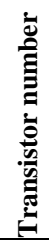 & 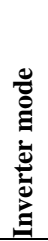 & 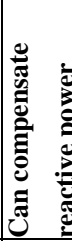 & 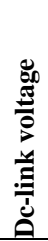 & نُّ & 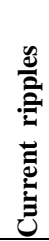 \\
\hline Boost & - & - & ++ & - & - & + & + & - \\
\hline Interleaved & + & + & + & - & - & + & - & + \\
\hline Half-bridge & + & ++ & + & + & + & - & - & - \\
\hline Bridgeless & + & + & + & - & - & + & + & - \\
\hline Bridgeless totem & + & + & + & - & - & + & - & - \\
\hline Full-bridge & +- & + & - & + & + & + & - & - \\
\hline
\end{tabular}

\section{EXPERIMENTAL RESULTS}

Since the simulation of PFC circuits could not define the final choice of PFC circuit the above described converters have been tested experimentally. This testing (like the simulation) has been provided at $25 \%$ and $75 \%$ of nominal output power. An example of the measured curves (the input current and voltage of the boost PFC) is given Fig. 15. The current is quite sinusoidal - current THD is 7\% at low load and $2 \%$ at high load.

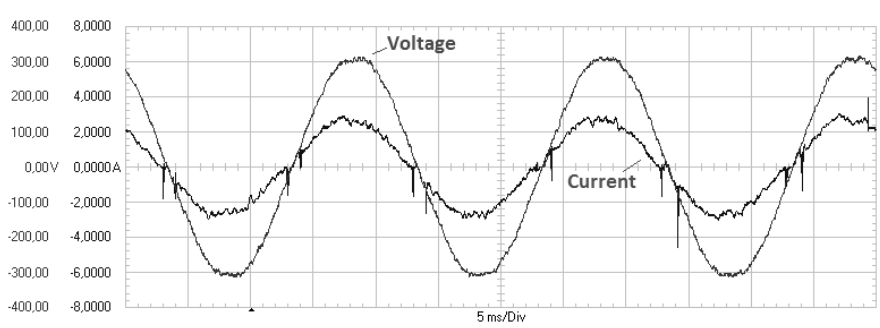

a) $25 \%$ of nominal power;

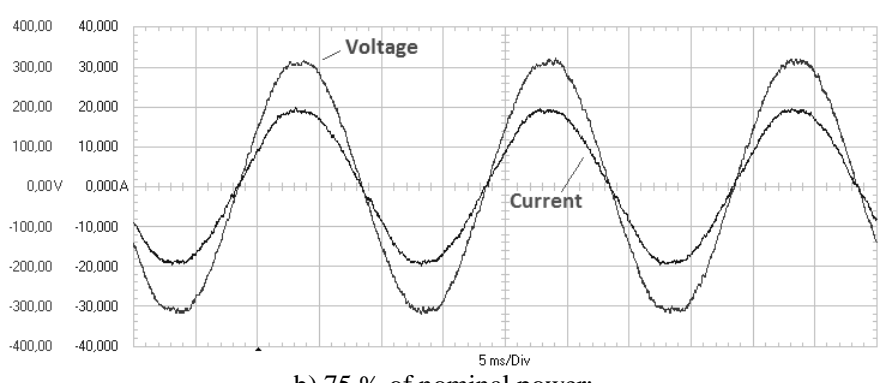

b) $75 \%$ of nominal power;

Fig. 15. Boost PFC converter measured current and voltages.

Other results obtained for all the discussed converters at $25 \%$ and $75 \%$ of power are listed in Table IV. The experiments were conducted with standard electrical grid (220-230V) on the input and with purely active load (laboratory rheostats) attached to DC-link. The voltage across DC-link during the experiments was kept at the level of $750 \mathrm{~V}$ for the half-bridge PFC and at the level of $375 \mathrm{~V}$ for all other circuits. The accuracy of measurement equipment was $0.5-2 \%$. For this reason the calculated efficiency is very approximate.
TABLE IV

EFFICIENCY OF ACTIVE PFC AT 75\% AND 25\% OF POWER

\begin{tabular}{|l|c|c|c|c|}
\hline \multirow{2}{*}{$\begin{array}{l}\text { Converter } \\
\text { topology }\end{array}$} & \multicolumn{2}{|c|}{ Efficiency (\%) } & \multicolumn{2}{c|}{ THD (\%) } \\
\cline { 2 - 5 } & $\mathbf{7 5 \%}$ & $\mathbf{2 5 \%}$ & $\mathbf{7 5 \%}$ & $\mathbf{2 5 \%}$ \\
\hline Boost & 93 & 94 & 2 & 7 \\
\hline Half-bridge & 90 & 87 & 4 & 15 \\
\hline Bridgeless & 94 & 91 & 4 & 10 \\
\hline Bridgeless totem & 92 & 92 & 4 & 10 \\
\hline Full-bridge & 91 & 91 & 13 & 30 \\
\hline Interleaved & 92 & 91 & 10 & 19 \\
\hline
\end{tabular}

The experiments with the basic bridgeless, bridgeless totempole and full-bridge PFC converters showed that they have high common-mode noise that influences the operation of control circuits. This noise has to be removed by additional filtering elements.

The experiments conducted with half-bridge PFC converter shows that it consumes very sinusoidal current (THD 4\%) from the grid. However, in contrast to the corresponding simulation results these experiments show low efficiency. There are many possible reasons for this lower efficiency. One of them - increased switching losses of the utilized switches at chosen switching frequency $(20 \mathrm{kHz})$.

Experiments with the interleaved boost converter show that it has smaller than the common boost PFC current ripples on its input. However, some undiscovered problem leads to significant deviation of the input current appearing close to the amplitude value that makes the resulting THD much higher (up to $\mathrm{THD}=10 \%$ ).

\section{V.CONCLUSIONS}

Six topologies of active PFC converter have been shortly described, simulated and tested experimentally.

Simulation shows that the bridgeless and half-bridge topologies have slightly higher efficiency and are good as PFC circuits that correspond to the initial analytical estimation. Both circuits at high power ensure input current with $\cos (\mathrm{f})$ near 1, THD near 3-5\%. At low power this circuits ensure input current with $\cos (\mathrm{f})$ in range of $0.95-0.99$ and THD in range of $20-40 \%$.

The half-bridge and full-bridge topologies allow ensures not only power factor correction but also consuming of reactive power of both types (capacitive/inductive). This phenomenon can be used to compensate the reactive power of other devices connected to the same grid.

Experimental result shows also that bridgeless topologies have very high common-mode noise and need to be improved. The reason of increased common-mode noise has to be identified and removed. Fixing of this problem may lead to significant improvement of the results of the bridgeless topologies of PFC.

Interleaved boost converter has a big potential of improvement because of the compensation of the current ripple in parallel boost branches as it has been shown through simulation. This topology, however, requires some additional experimental investigation. 
The overall conclusion after the experiments gives the preference to the boost bridge topology due to its simple construction and control providing at the same time high efficiency and a rather small THD. Implementation of the other PFC rectifiers requires an advanced investigation of these converters.

\section{REFERENCES}

[1] Koen De Gusseme, David M. Van de Sype, Jeroen Van den Keybus, Alex P. Van den Bossche, Jan A. Melkebeek, " Fully Equipped Half Bridge Building Block for Fast Prototyping of Switching Power Converters", 35th Annual IEEE Power Electronics Specialists Conference, Aachen, Germany, 2004

[2] A.Stepanov, A.Galkin, L.Bisenieks, A.Sokolovs. "Development of a modular power converter", 50th International Scientific Conference, Riga, Latvia, October 11-13, 2009

[3] 2. A. Pandey, D. P. Kothari, A. K. Mukerjee, B. Singh, "Modelling and simulation of power factor corrected AC-DC converters", International Journal of Electrical Engineering Education, Vol.41, Issue. 3 pp. 244264, 2004

[4] 3. T. Ernö and M. Frisch, "Second generation of PFC solutions," Power Electronics Europe, Issue 7, pp. 33-35, 2004

[5] 4. L. Huber, Y. Jang, M. M. Jovanović, Performance Evaluation of Bridgeless PFC Boost Rectifiers, Applied Power Electronics Conference, APEC 2007.

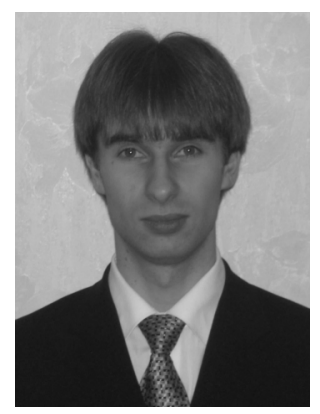

Andrew Stepanov has received his bachelor and master degree in Riga Technical University (in 2004 and 2006, respectively). The thesis was focused on research and development of uninterruptible power supplies containing specific energy storages - supercapacitors. In 2010 completed doctoral study program and at the given time is working on his doctoral thesis also devoted to uninterruptible power supply systems.

Andrew Stepanov has been employed in Riga Technical University, Department of Power Electronics and Electrical Technologies as a scientific assistant. Currently he is employed in the same institution as a researcher.

The research interests of Andrew Stepanov are related to uninterruptible power supplies and such alternative energy sources like solar and wind energy as well as to new technologies of storing of electrical energy.

Andrew Stepanov is an IEEE member.

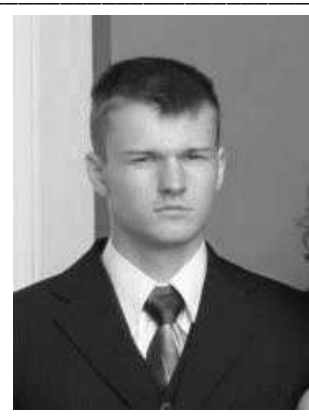

Valdis Bogdan received his bachelor (2008) and master (2010) degree in Riga Technical University in Faculty of Power and Electrical Engineering in Computer Control of Electrical Technology study program. The bachelor thesis was focused on DC/DC converters, in particular, on analysis of dynamic operation. The master thesis was devoted to elaboration of automatics of high-pressure boiler for Riga's TEC-1. His studies were mainly focused on electrical drive and on the development of automation based on microprocessors. Area of scientific interests of systems and elements of electrical drives. Valdis Bogdan covers microprocessor control

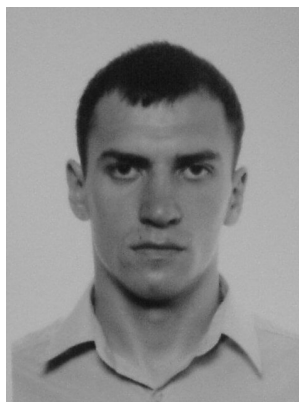

Pavels Suskis has presented his Bachelor Science degree and Master Science with Engineer qualification in Riga's Technical University, Faculty of Energetics and Electrotechnics in 2008 and 2010, respectively. His bachelor thesis was focused on "Frequency converter applying to crane drive" while master thesis and engineer qualification project was devoted to research and development of control system for voltage source inverter. Research interests of Pavels Suskis are in the fiend of intelligent microprocessor control of electric drives.

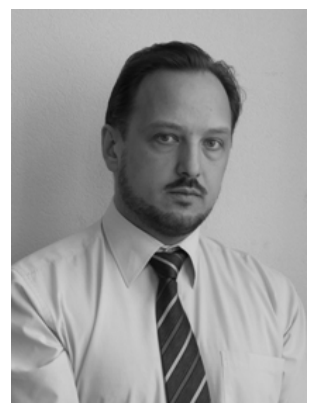

Ilya Galkin received his Bachelor's (1994), Master's (1996) and Doctor's (2001) Degrees in the field of electrical engineering at Riga Technical University, Faculty of Power and Electrical Engineering, Department of Power Electronics and Electrical Technologies. The main research field includes design and applications of matrix converters. In particular it regards integrated designs with the matrix converters, smart control of their semiconductor switches, thermal and conductor's design. Another research field includes smart power supplies for various applications, for example, for LED lighting and uninterruptible power supplies.

The working experience of Ilya Galkin includes 6 year of practical engineering job at research and manufacturing enterprise "Lasma" (Latvia) in the field of elaboration and development industrial automatics, as well as 14 years of research and educational job at Riga Technical University. At the given time he is professor at the Department of Power Electronics and Electrical Technologies of RTU-EEF-IEEI. Ilya Galkin is the author of various publications.

Ilya Galkin is IEEE member since 2006 in societies of Power Electronics, Industrial Electronics, Automatic Control and Education. 